\title{
P.R.L. Platelet Rich Lipotransfert: Our Experience and Current State of Art in the Combined Use of Fat and PRP
}

\author{
V. Cervelli, ${ }^{1}$ I. Bocchini, ${ }^{1}$ C. Di Pasquali, ${ }^{1}$ B. De Angelis, ${ }^{1}$ G. Cervelli, ${ }^{1}$ C. B. Curcio, ${ }^{1}$ \\ A. Orlandi, ${ }^{2}$ M. G. Scioli, ${ }^{2}$ E. Tati, ${ }^{1}$ P. Delogu, ${ }^{1}$ and Pietro Gentile ${ }^{1}$ \\ ${ }^{1}$ Plastic Surgery Department, Tor Vergata University of San Salvatore, Lauro Place 15, 00186 Rome, Italy \\ ${ }^{2}$ Anatomic Pathology, Tor Vergata University of Rome, Rome, Italy
}

Correspondence should be addressed to Pietro Gentile; pietrogentile2004@libero.it

Received 5 April 2013; Revised 28 May 2013; Accepted 26 August 2013

Academic Editor: Pedro Cabrales

Copyright (C) 2013 V. Cervelli et al. This is an open access article distributed under the Creative Commons Attribution License, which permits unrestricted use, distribution, and reproduction in any medium, provided the original work is properly cited.

\begin{abstract}
The authors report their experience about the use of P.R.L. PLATELET RICH LIPOTRANSFERT method (platelet rich plasma mixed fat grafting) in 223 patients affected by soft tissue defects (ulcers, Romberg syndrome, Hemifacial atrophy, loss of substance, and signs of aging). This paper introduces the reader to PRP therapy and reviews the current literature on this emerging treatment modality, showing at the current clinical use of PRP in plastic and reconstructive surgery, with description of innovative methods and future prospects. This technique provides a promising alternative to surgery by promoting safe and natural healing. Here recent studies concerning the use of PRP in the treatment of chronic ulcers and soft tissue defect are reviewed.
\end{abstract}

\section{Introduction}

In Europe, and more recently in the United States, an increased trend emerged in the use of autologous blood products to facilitate tissue regeneration and healing [1]. Platelet rich plasma is an autologous blood product by a selective removal or exchange of either packed red blood cells, leucocyte-rich or platelet-rich layers, or plasma, with a continuous flow blood separator machine.

Its use of PRP has been firstly described in 1975 by Oon and Hobbs [2]. After its description, the first clinical application was performed by Ferrari et al. in 1987 [3], in open heart surgery, to avoid an excessive transfusion of homologous blood products. After that, its application has been safely used and documented in many fields, including maxillofacial surgery $[4,5]$, aesthetic plastic surgery [6$8]$, treatment of soft-tissue ulcers $[9,10]$, and regenerative surgery.

In the 1999 Anitua [11] reported the preliminary clinical evidence of the beneficial effect of the use of P.R.P. in bone regeneration using plasmapheresis. After that he published a numerous reports about the use of PRP in tendon healing [12], orthopedic sport injuries [13], dental implants [14], and chronic cutaneous ulcers [15]. In 2009 he reported a study that described the fibroblastic response to the application of different preparations rich in growth factors [16].

This paper is a focused review of the literature about the clinical approaches of the use of PRP, describing also the experience of authors who coined the term of P.R.L. PLATELET RICH LIPOTRANSFERT (method of mix and use of platelet rich plasma with fat grafting) and methods of application updated.

Scope of the Paper. The aim of this paper is to analyze the efficacy of PRP mixed to fat tissue in wounds and soft tissue defects. The authors evaluate here the clinical efficacy of different concentration of PRP and compare also the results obtained with a control group treated not with PRP or some other blood derivate. This paper would also provide a concise compilation of recent advances in this field.

\section{Materials and Methods}

The authors used [17] several concentration of PRP, from $0.2 \mathrm{~mL}$ to $0.5 \mathrm{~mL}$, to be added to fat tissue for wounds and soft tissue defects. The objective of the study was to identify the 


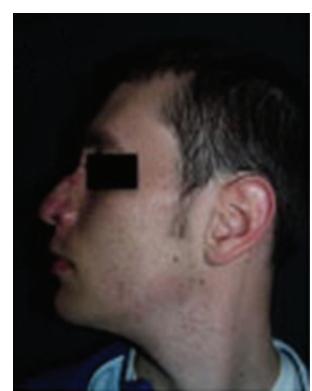

(a)

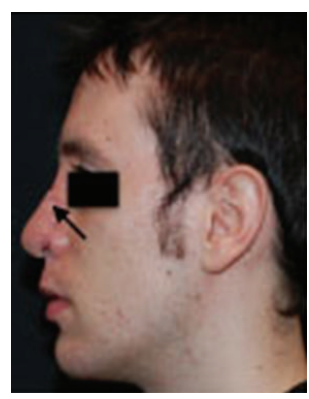

(f)

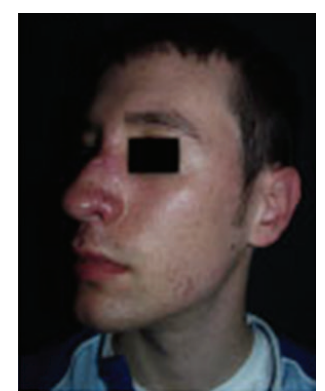

(b)

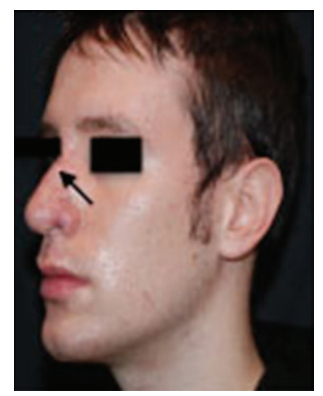

(g)

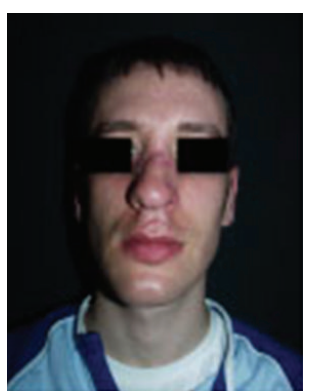

(c)

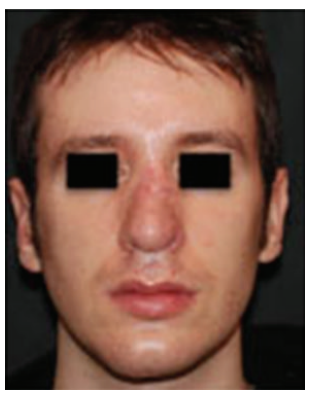

(h)

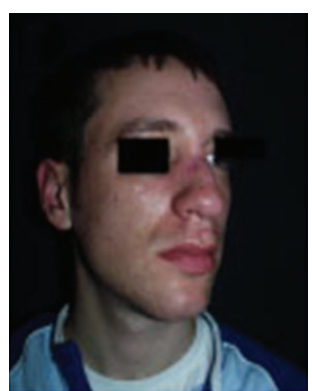

(d)

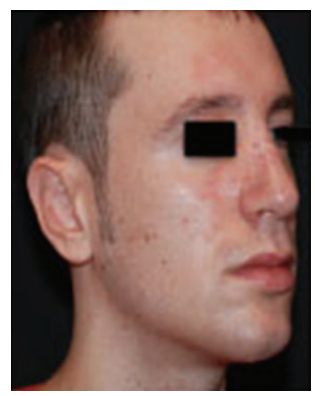

(i)

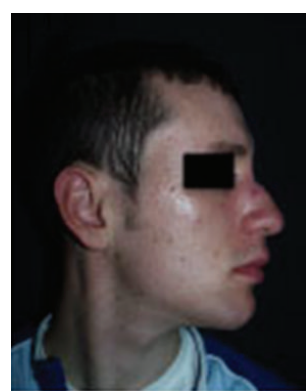

(e)

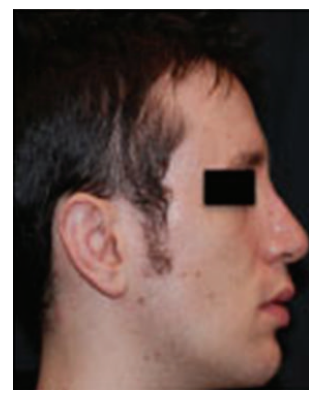

(j)

FiguRE 1: Analysis of patients affected by outcomes of scars. (a) Preoperative situation in lateral left projection. (b) Preoperative situation in $3 / 4$ left projection. (c) Preoperative situation in frontal projection. (d) Preoperative situation in 3/4 right projection. (e) Preoperative situation in lateral right projection. (f) Postoperative situation in lateral left projection. (g) Postoperative situation in $3 / 4$ left projection. (h) Postoperative situation in frontal projection. (i) Postoperative situation in 3/4 right projection. (j) Postoperative situation in lateral right projection.

optimal concentration (quantity in $\mathrm{mL}$ in clinical practice) of platelet gel that might be added to each $\mathrm{mL}$ of adipose tissue harvested by the method of Coleman $[18,19]$. The authors V. Cervelli and P. Gentile coined a term of P.R.L. PLATELET RICH LIPOTRANSFERT to describe a method of mix and use of platelet rich plasma with fat grafting.

2.1. Patients. From July 2009 to July 2012, 223 patients (134 males and 89 females), aged from 18 to 75 years (mean age $=$ 36.6 years), underwent to infusion of P.R.L. PLATELET RICH LIPOTRANSFERT in the Department Plastic and Reconstructive Surgery of the University of Tor Vergata, Rome. The patients were divided into three groups:

Group A: composed of 132 patients affected by softtissue defects with loss of volume and elasticity, associated with signs of aging (70 males and 62 females);

Group B: composed of 87 (63 males and 24 females) patients affected by chronic venous lower extremity ulcers;

Group C: composed of 4 patients affected by Romberg syndrome and Hemifacial atrophy (1 male and 3 females).

Patients of Group B (venous low extremity ulcers) are affected by the following comorbidity: dislipidemie in 16 patients (18\%), cardiological disease in 15 patients $(17 \%)$, hypertension in $10(12 \%)$, diabetes in $32(37 \%)$, arteriopathy of lower extremity in $4(5 \%)$, and no comorbidity in 10 patients $(12 \%)$.
The authors compared their results with three homogeneous control groups, presenting these features:

Control Group A: 132 patients affected by outcomes of scars (70 males and 62 females) treated with fat injection only (Figure 1);

Control Group B: 87 patients affected by venous low extremity ulcers (60 males and 27 females) treated with curettage and application of biomaterials (hyaluronic acid and collagens);

Control Group C: 4 patients affected by Romberg Syndrome (2 males and 2 females) treated with fat injection only.

General exclusion criteria were: platelet disorders, thrombocytopenia, antiaggregating therapy, bone marrow aplasia, uncompensated diabetes, sepsis, and cancer. Local exclusion criteria were infection or diastasis.

2.2. Clinical Evaluation Methods. Tissue regeneration was evaluated by the analytical comparison of pre- and postoperative images. In addition three methods for the evaluation of outcomes were used: (1) team evaluation, (2) NMR (nuclear magnetic resonance) and Ultrasound, (3) patient self-evaluation.

The Team evaluation is an evaluation method based on clinical observation, using a scale of six values (excellent, good, discreet enough, poor, and inadequate). The factors/variables, considered were pigmentation, vascularization, pliability, thickness, itching, and pain. 
The patient evaluation is an evaluation method based on clinical observation, using a scale of six values (excellent, good, discreet enough, poor, and inadequate).

In addition, in complicated cases, a high-resolution CT scan with 3D imaging for a better view of the anatomical structures was performed. In the venous low extremity of patients affected by ulcers a biopsy punch $2-4 \mathrm{~mm}$ of diameter was collected.

A followup of the patients was performed at the second and fifth weeks and at 3, 6, and 12 months and then annually.

\subsection{Platelet Rich Plasma Preparation. The traditional PRP} preparation consisted in a slow centrifugation; platelets remain suspended in the plasma, while the leukocytes and erythrocytes are displaced to the bottom of the tube. A rapid centrifugation can cause mechanical forces and can raise the temperature, inducing changes in the ultrastructure of platelets that stimulate partial activation, with a consequent loss of its content [20].

Generally, the authors prepared PRP (using centrifuge at $1100 \mathrm{~g}$ for $10 \mathrm{~min}$ ) from a small volume of blood $(18 \mathrm{cc}$ ) according to the Cascade $[17,20,21]$ method and in all cases with approval of Transfusional Service.

Anitua et al. [11, 14-16, 22] reported the use of two centrifuges; sample of blood was collected into $3.8 \%$ (wt/vol) sodium citrate and was centrifuged either at $4500 \mathrm{~g}$ for $12 \mathrm{~min}$ at $4^{\circ} \mathrm{C}$ to obtain PP-plasma or at $460 \mathrm{~g}$ for $8 \mathrm{~min}$ to obtain PRplasma. Calcium chloride was added to PP- and PR-plasma of each donor at a final concentration of $22.8 \mathrm{mM}$ [23].

Standard cell separators and salvage devices can be used to produce platelet-rich plasma [24]. These devices operate on a unit of blood and typically use continuous-flow centrifuge bowl or continuous-flow disk separation technology and both a hard (fast) and a soft (slow) spin, yielding platelet concentrations from two to four times baseline $[25,26]$. Such devices include the CATS (Fresenius, Wilmington, DelDE), sequestra (Medtronic, Minneapolis, MN) and Haemonetics Cell Saver 5 (Haemonetics Corp., Braintree, MA), [25-27].

Many surgical procedures require the use of relatively small volumes of platelet-rich plasma [28].

Consequently, small, compact office systems that produce approximately $6 \mathrm{~mL}$ of platelet-rich plasma from 45 to $60 \mathrm{~mL}$ of blood have been developed [29-31].

There are many of such systems, including the GPS (Biomet, Warsaw, IN), the PCCS (Implant Innovations, Inc., Palm Beach Gardens, FL), the Symphony II (DePuy, Warsaw, IN), the SmartPReP (Harvest Technologies Corp., Norwell, MA), and the Magellan (Medtronic, Minneapolis, MN) [25, 27, 29-31]. Although all operate on a small volume of drawn blood ( 45 to $60 \mathrm{~mL}$ ) and on the principle of centrifugation, these systems differ widely in their ability to collect and concentrate platelets, with approximately 30 to 85 percent of the available platelets collected and from a less than 2 -fold to an approximately 8 -fold increase in the platelet concentration over baseline $[25,26]$.

The authors used in the personal experience CascadeFibrinet (Cascade Medical Enterprises, Plymouth, Devonshire, UK), Vivostat (Vivostat A/S, Borupvang 2, DK-3450 alleroed, Denmark), and Regen (Regen Lab, En Budron B2, CH-1052 Le Mont-sur-Lausanne, Switzerland).

In general, a lot of systems do not concentrate on the plasma proteins of the coagulation cascade [25, 27]. The concentration of plasma proteins above baseline can be achieved through secondary ultrafiltration, as done with the UltraConcentrator (Interpore Cross, Irvine, CA) and the Access System (Interpore Cross), in which the buffy coat collected from a centrifugation stage is passed through hollow fibers with an effective pore size of $30 \mathrm{kDa}$.

With this system, up to two-thirds of the aqueous phase is removed by filtration; thus, the concentrations of the retained plasma proteins and formed elements are correspondingly increased [32-34].

2.4. Platelet Rich Lipotransfer Preparation. Fat harvesting was performed in the same moment of the PRP preparation. We harvested fat tissue in the abdominal region using some specific cannula, with diameters of 2 to $3 \mathrm{~mm}$ and $1.5 \mathrm{~mm}$, for grafting (Coleman Kit, Tucson, AZ) [15, 16, 18, 20, 34]. We took the plungers of syringes and closed them with their caps then positioned them flatly in the sterile centrifuge, to maintain asepsis. The syringes were processed for $3 \mathrm{~min}$ at $3,000 \mathrm{rpm} / \mathrm{min}[17,18,20,34]$. This purified body fat combined with PRP was put in $1 \mathrm{~mL}$ syringes and aseptically reinjected using the specific microcannulas (Coleman Kit, Tucson, AZ) $[18,34]$ to implant it into the area to be treated. Skin incisions about $2 \mathrm{~mm}$ in diameter to permit passage of the cannula were made using a number 11 scalpel blade. The implant location destined to receive the implant was selected by an accurate study of the necessary corrections [17, 21, 24, 35]. Fat tissue combined with PRP was implanted at different levels in small tunnels around the margins created earlier by forcing the cannula with precise controlled movements. A small quantity of fat cells was laid, one or two at a time, during the exiting movement of the cannula to create a large grid to correct the vascular development around each fat cell. Layers of the aligned single cells were laid to increase the contact surface between the receiving tissue and the implant. This technique was of fundamental importance in allowing each single layer deposited to survive through the few days necessary for the growth of the blood vessels that would nourish them permanently $[9,36]$. We closed the access incisions with 5-0 nylon stitches, and a compressive bandage was not applied.

The fat volume was injected in the selected areas according to the defect to be corrected; in the scars the volume ranges between $10 \mathrm{cc}$ and $80 \mathrm{cc}$, and in the ulcers ranges between $5 \mathrm{cc}$ and $50 \mathrm{cc}$, in the Romberg syndrome ranges between $60 \mathrm{cc}$ and $140 \mathrm{cc}$.

\section{Results}

3.1. In Vivo: Influence of Platelet-Rich Plasma in Tissue Regeneration and during Fat Grafting Surgical Procedures. Previously the authors published in Tissue Eng 2009 [20] their experience about the application of platelet rich plasma in plastic surgery. The authors added $0.5 \mathrm{~mL}$ or $0.4 \mathrm{~mL}$ of 


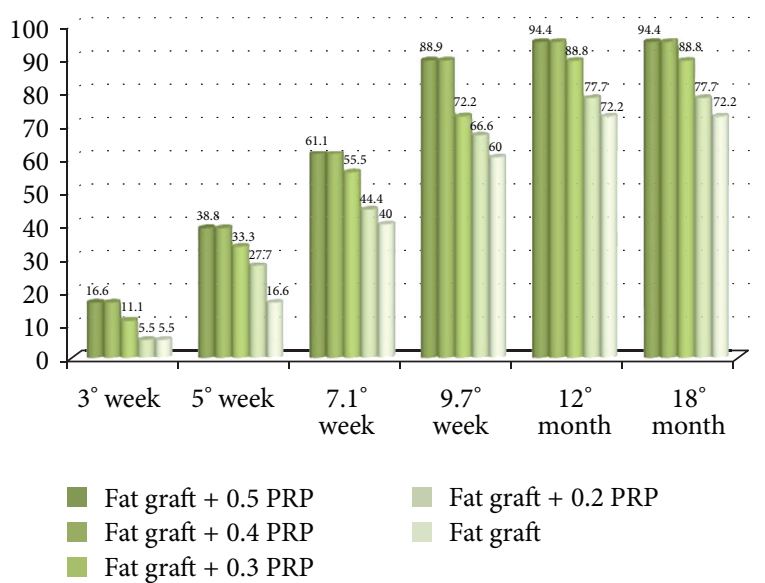

FIGURE 2: Bar graphs showing effects of PRP at different concentrations on percentages of skin chronic ulcer reepithelization.

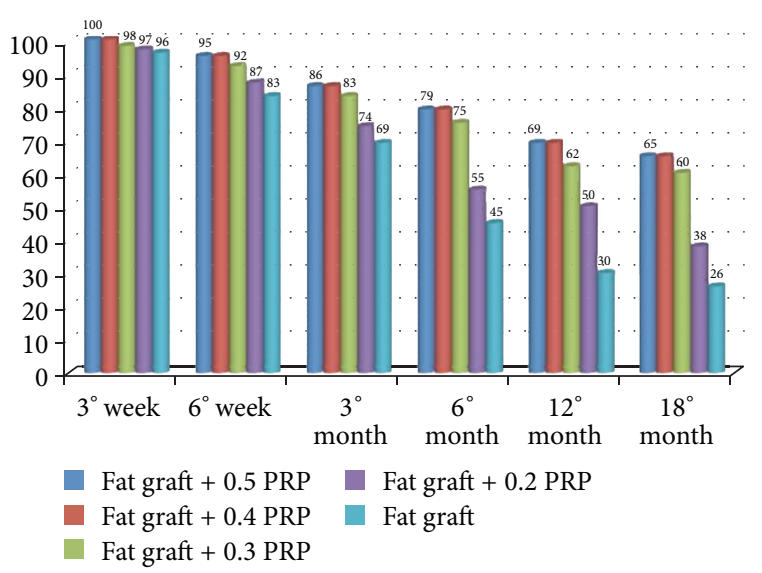

FIGURE 3: Bar graphs showing effects of PRP at different concentrations on percentages of maintenance of restored fat.

PRP per each $\mathrm{mL}$ of fat tissue (Figure 4). They observed that $61.1 \%$ and $88.9 \%$ of chronic lower extremity ulcers $100 \%$ reepithelization during an 7.1 and 9.7-week (average) course of twice-daily wound treatment with PRP suspended on a collagen base, respectively, compared with 40 and $60 \%$ of the first control group $(n=10)$, respectively, treated with hyaluronic acid and collagen medication.

When the authors added $0.3 \mathrm{~mL}$ of PRP per each $\mathrm{mL}$ of fat tissue, they observed $55.5 \%$ and $72.2 \%$ of chronic lower extremity ulcers $100 \%$ reepithelization during an 7.1 and 9.7week average.

When the authors added $0.2 \mathrm{~mL}$ of PRP per each $\mathrm{mL}$ of fat tissue, they observed $44.4 \%$ and $66.6 \%$ of chronic lower extremity ulcers $100 \%$ reepithelization during an 7.1 and 9.7week average. We also observed in patients affected by soft tissue defect treated with reconstructing three dimensional projection by fat grafting and PRP at concentration of $0.5 \mathrm{~mL}$ or $0.4 \mathrm{~mL}$ per each $\mathrm{ml}$ of fat tissue, a $70 \%$ maintenance of contour restoring and three-dimensional volume after 1 year, and only $31 \%$ in control patients $(n=10)$ treated 200 with only fat grafting; when we used $0.3 \mathrm{~mL}$ and $0.2 \mathrm{~mL}$ of
PRP per each $\mathrm{mL}$ of fat tissue, we observed a $62 \%$ and $50 \%$ maintenance of contour restoring after 1 year.

3.2. In Vitro: Adipose Tissue Derived Stem Cells Isolation and Expansion. Liposuction aspirates were washed three times with phosphate-buffered saline (PBS), suspended in an equal volume of PBS and $0.1 \%$ collagenase type I (C130; Sigma-Aldrich, Milan, Italy), and prewarmed to $37^{\circ} \mathrm{C}$ [37, 38]. Adipose tissue was placed in a shaking water bath at $37^{\circ} \mathrm{C}$ with continuous agitation for $60 \mathrm{~min}$ and centrifuged for $10 \mathrm{~min}$ at $600 \mathrm{~g}$ at room temperature. The supernatant, containing mature adipocytes was aspirated. The stromal vascular fraction pellet was resuspended in erythrocyte lysis buffer $\left(155 \mathrm{mM} \mathrm{NH}_{4} \mathrm{Cl}, 10 \mathrm{mM} \mathrm{KHCO}_{3}\right.$, and $\left.0.1 \mathrm{mM} \mathrm{EDTA}\right)$ and incubated for $5 \mathrm{~min}$ at room temperature [28]. After centrifugation for $5 \mathrm{~min}$, the pellet was resuspended in few $\mu \mathrm{L}$ of growth medium and passed through a $100 \mu \mathrm{m}$ Falcon strainer (Becton \& Dickinson, 129 Sunnyvale, CA, USA), and cellular population was counted using haemocytometer. In twelve patients randomly selected, nucleated SVF cells were 317,578 +25,645 per $\mathrm{mL}$ of lipoaspirate. Then digestion was plated in DMEM (Euroclone, Pavia, Italy) supplemented with $10 \%(\mathrm{v} / \mathrm{v})$ fetal bovine serum (FBS; Euroclone, Pavia, Italy), $2 \mathrm{mM} \mathrm{L}$-glutamine, $100 \mathrm{U} / \mathrm{mL}$ penicillin, $100 \mathrm{~g} / \mathrm{mL}$ streptomycin and $0.25 \mathrm{~g} / \mathrm{mL}$ fungizone (Invitrogen, Milan, Italy), at a density of $2500-5000 \mathrm{cell} / \mathrm{cm}^{2}$ of surface area. This initial passage of the primary cell culture was referred as passage $0(\mathrm{PO})$. After 48 hours of incubation at $37^{\circ} \mathrm{C}$ at $5 \%$ $\mathrm{CO}_{2}$, the cultures were washed with PBS and maintained in stromal media until they achieved $75 \%-90 \%$ confluence [37, 38]. Adipose tissue derived stem cells (ASCs) were passaged by trypsin $(0.05 \%)$ digestion and plated at a density of 5,000 cells $/ \mathrm{cm}^{2}$ (P1). Medium was changed every 3 days. To demonstrate cultured ASCs differentiation potential, adipogenic and osteogenic differentiation was obtained in 3rd passage confluent cells according to previously published methods [39]. To assess mineralization corresponding to osteogenic differentiation, intracellular calcium deposits were stained with von Kossa. Images of cultured cells after Oil Red O and von Kossa staining were obtained through a digital telecamera (Nikon, model 152 Dxm1200F), connected to a computer utilizing Nikon ACT-1 software with a light microscope at 200x magnification.

\subsection{Platelet-Rich Plasma Concentrations Increases Adipose} Tissue Stem Cells Number In Vitro. ASCs at the third passage were seeded at a density of 5000 cells $/ \mathrm{cm}^{2}$ in 24 -well plates and incubated for $24 \mathrm{~h}$ in DMEM containing 10\% FBS. Medium was then replaced with DMEM containing 0.1\% FBS for starvation. After $24 \mathrm{~h}$ the medium was changed, for the treatment, with DMEM 10\% FB (control) and DMEM $10 \%$ FBS 5\% PRP. The medium containing the respective supplements was replaced every 2 days. After $0,2,4,6$, and 8 days of culture, cells were digested with $0.25 \%$ trypsin solution and then counted, with trypan-blue exclusion, using hemocytometer. Cell viability by trypan blue exclusion was consistently more than $98 \%$. The reported results were 


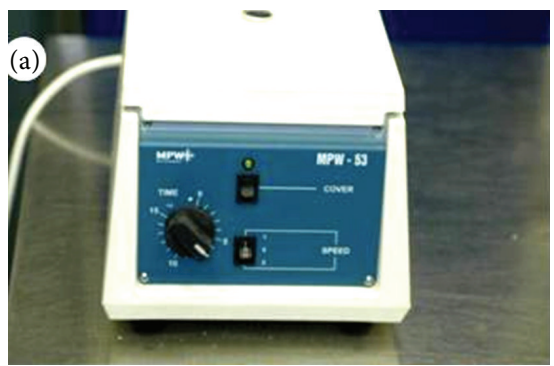

(a)

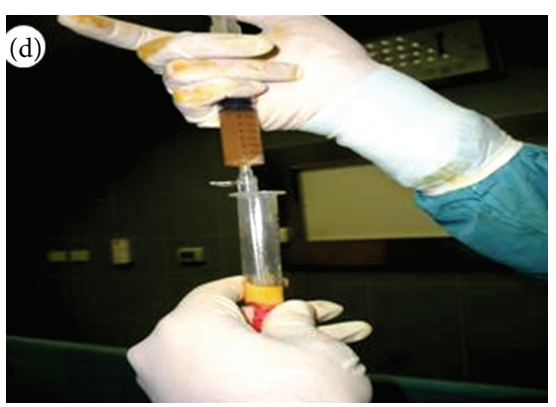

(d)

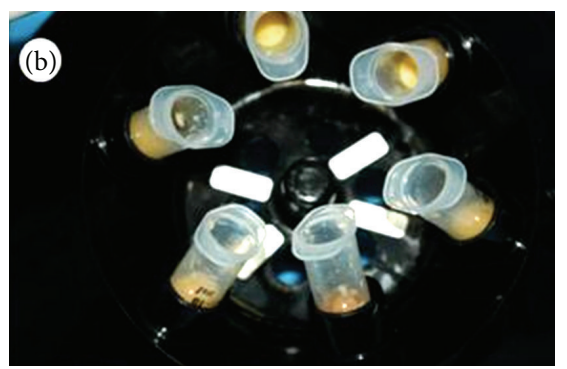

(b)

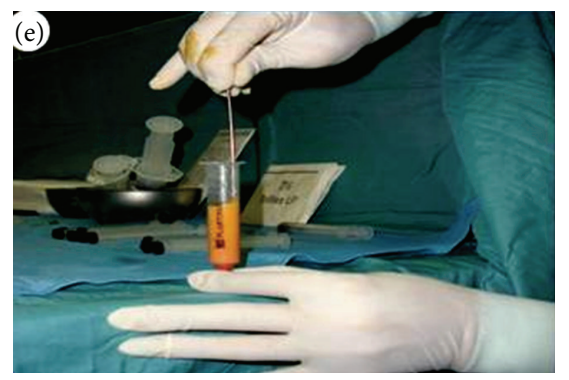

(e)

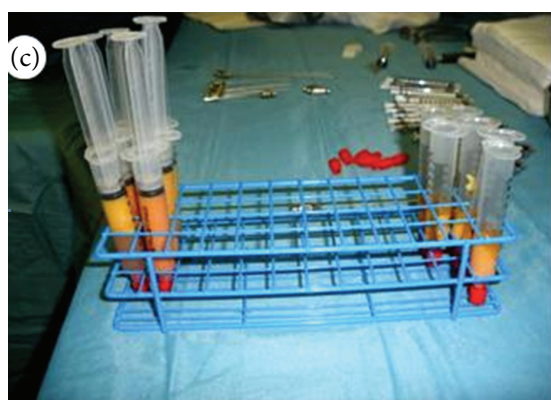

(c)

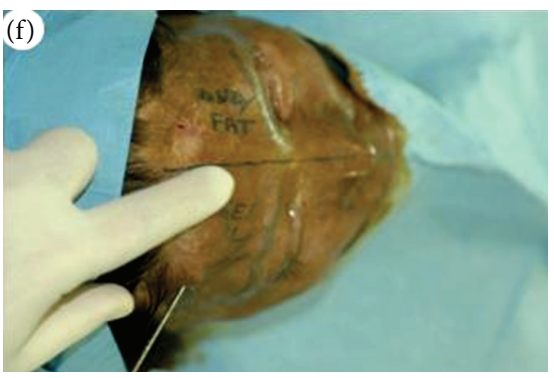

(f)

FiguRE 4: P.R.L. PLATELET RICH LIPOTRANSFERT procedure. (a) Platelet rich plasma preparation according to Cascade centrifuge; (b) fat graft preparation according to Coleman Centrifuge; (c) purified fat graft after centrifugation; (d) addition of PRP to purified fat graft; (e) mix of $0.4 \mathrm{~mL}$ of PRP with $1 \mathrm{~mL}$ of fat graft in a $10 \mathrm{~mL}$ luer-look syringes (P.R.L. PLATELET RICH LIPOTRANSFERT); (f) injection of P.R.L. PLATELET RICH LIPOTRANSFERT according to lipostructure technique.

the mean value of triplicate samples. Each assay was performed twice. As reported previously [20], PRP induced an increase of ASC number without any morphological changes compared with control. There was a statistically significant increase, by around fourfold, at 4 and 6 days, when cells were preconfluent $(P<0.02)$. After 8 days, at confluency, there was a threefold increase of adipose ASC number in PRP cultures compared to controls. Oil Red O staining did not reveal any significant difference in intracytoplasmic lipid accumulation compared with PRP-treated and control ASCs. The authors reported the effects of platelet-rich plasma on proliferation of human adipose-derived stem cells (Figure 5). In Table were presented growth curves that show the dosedependent increase of proliferation with PRP. In detail growth curves documented that PRP increased ASC proliferation in a dose-dependent manner (EC50 $=15.3 \pm 1.3 \% \mathrm{vol} / \mathrm{vol})$, with a fourfold increase of cell number at $5 \%(\mathrm{vol} / \mathrm{vol})$ dosage compared with control after 4 days $(P<0.05)$.

\section{Discussion and PRP Therapies}

The present findings demonstrated that the different concentration of PRP (ranging from $0.2 \mathrm{~mL}$ to $0.4 \mathrm{~mL}$ ) influence the in vitro adipose derived mesenchymal stem cell proliferation. Higher concentration was observed at a concentration of $0.4 \mathrm{~mL}$. When 0.4 or $0.5 \mathrm{~mL}$ PRP was injected mixed with $1 \mathrm{~mL}$ of centrifuged fat, it favoured growth and restored fat volume maintenance, confirming data observed with other surgical procedures, including periodontal $[40,41]$ and oral surgery $[4,22,42,43]$, maxillofacial surgery $[4,5]$, aesthetic plastic surgery [6-8], spinal fusion [44-46], heart bypass surgery [47], and treatment of soft tissue ulcers $[9,10]$ (Figure 3).

PRP, being produced during surgical procedures under sterile conditions, is easy to produce and safe to use; moreover, PRP is lacking of surface antigens, responsible of potential allergic reactions [48].

Our results clearly documented that the use of PRP during fat grafting favours adipose tissue maintenance and survival. Moreover, our in vitro data are in accordance with the hypothesis that PRP stimulates adipose tissue regeneration, as demonstrated in controlled animal studies for both soft and hard tissues [18]. In addition, in comparing to lipofilling $[19,34,49]$ where fat cells are laid in rows without solution of continuity, implant survival is likely derive from reduction of fat necrosis due to improved neoangiogenesis in the implanted area.

The authors feel that there are new issues in the literature about the selection of the most appropriate regenerative methods. Indeed, there are many publications regarding the use of PRP with/without fat graft in plastic and reconstructive surgery; the authors divided the review of the application of PRP in the following pathologies.

4.1. PRP in the Treatment of Chronic Ulcers. About this topic there is not paper in the literature describing the use of PRP mixed with fat graft but a large number of paper based on use of only PRP or PRP with biomaterials (hyaluronic acid 


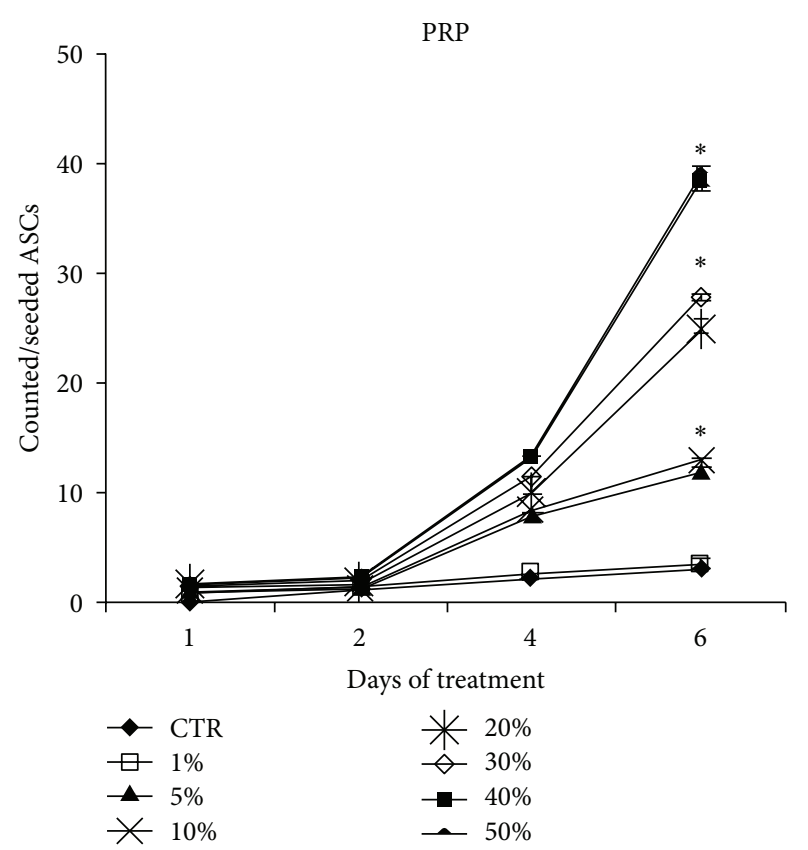

FIGURE 5: Effects of platelet-rich plasma on proliferation of human adipose-derived stem cells. Growth curves show the dosedependent increase of proliferation with PRP.

and collagen). Nonhealing cutaneous wounds represent a challenging problem and are commonly related to peripheral vascular disease, infection, trauma, neurologic, and immunologic conditions, as well as neoplastic and metabolic disorders.

These chronic ulcerative wounds represent significant impact both psychologically and socioeconomically. An analysis of the surfaces of chronic pressure wounds (decubitus ulcers) revealed a decreased growth factor concentration compared with acute wound [36]. In a study by Crovetti et al. [50], 24 patients with chronic skin ulcers were treated with a series of PRP Gel treatments. Nine patients demonstrated complete wound healing. In these subgroups, one wound reopened at 4 months. There were two reports of wound infection, both with positive Staphylococcus Aureus which were successfully treated with oral antibiotics. There were no adverse effects encountered and all patients noted decreased pain. 54242 Another wound study by McAlee et al. [51], involved 24 patients with 33 chronic nonhealing lower extremity wounds.

Patients failed conservative treatment for 6 months with a lack of reduction of surface area. The wounds were injected with PRP every 2 weeks. Successful wound closure and epithelization was obtained in 20 wounds. The mean time for closure was 11.15 weeks. Five wounds displayed no improvement [51]. These findings were particularly significant because all patients had failed previously available treatment methods.

Rigotti et al. [52], reported the use of only PRP in skin and soft-tissue losses on the basis of its bactericidal and cell proliferation promoting properties.
The authors described the use of fat grafting combined with platelet-rich plasma for chronic lower-extremity ulcers [21], evaluating the healing rate of skin chronic ulcer, according method of Kazakos [49], with minor modifications (Figure 2).

4.2. Use of PRP in Soft Tissue Defect. Powell et al. [53], describe anti-inflammatory properties with reduced edema and ecchymosis associated with the autologous platelet gel in eight women after deep-plane rhytidectomy (face lifting).

PRP was also shown to be effective in stopping capillary bleeding in the surgical flaps of a series of 20 patients undergoing various cosmetic surgery (face lift, breast size changes, or neck lifts) reported by Man [54].

Anderson [55] reported the use of fat tissue without PRP in patients affected by Romberg syndrome disease and facial defects. In addition, they recently reported interesting cases treated with rhytidoplasty combined with pursing plication suspension sutures and lipoinjection [56].

Recently, the authors described the use of fat graft with platelet rich plasma [35] and with only lipostructure technique [36] in patients affected by Romberg syndrome.

Lipostructure evolved from lipofilling and is better known as Coleman's technique $[18,19]$. In fact Coleman is the pioneer in the use of fat graft with lipostructure in the facial recontouring [19].

In addition Yoshimura et al. [57] describe a new methods and new technologies in the use of fat grafting. In fact, they use a cell-assisted lipotransfer (CAL) for cosmetic breast augmentation using adipose derived stem/stromal cells. In CAL, autologous adipose derived stem (stromal) cells (ASCs) are used in combination with lipoinjection. A stromal vascular fraction (SVF) containing ASCs is freshly isolated from half of the aspirated fat and recombined with the other half. This process converts relatively ASC poor aspirated fat to ASCrich fat.

A new aim could be the use of SVF isolated from half of fat tissue mixed with platelet rich plasma and recombined with the other half.

4.3. PRP in the Treatment of the Scars. Azzena et al. [58] hypothesized that autologous platelet-rich plasma (APRP) could be used as an in vivo adipocyte delivery system to favour cell survival and to stimulate early recruitment of microcapillaries to the site of implantation and treated a patient affected by adherent scar.

Zocchi [59] identified a few points for the readers to consider. (1) The cutting edge for fat transplantation is to treat the fat tissue not only as a volume replacement but also as a tissue regenerator, as a vehicle carrying its stromal fraction very rich in precursor cells, and as stem cells into the injection site. (2) It is mandatory to remember that this type of tissue manipulation should be performed only by well trained surgeons in well equipped and reliable facilities. (3) The use of platelets gel even for other clinical applications is still controversial, still not so easy for daily practice, still limited by laws and regulations, and still quite expensive. 


\section{Current and Future Challenges}

This work suggest two fundamental points: first, PRP added in concentration of $0.4 \mathrm{~mL}(40 \%)$ per each $\mathrm{mL}$ of fat tissue favours an optimal ASCs proliferation with correct architectural adipocytes distribution, 58298 better cell-to-cell interaction, adipose tissue growth, and differentiation from ASCs; this offers early protection from surrounding inflammatory events [60]. Secondly, PRP-induced early development of neoangiogenetic microcapillary network [61] favours the delivering of proper nutrient and oxygen levels to grafted cells. Actually, there are the several questions left to be solved in the immediately future of this exciting therapy: first, we shall have to explore which of the growth factors that PRP contain is best for tissue regeneration in plastic and reconstructive surgery; second, standardization of the use of PRP mixed with fat graft as a therapeutic product, and third, clinical and in vitro evaluation of the products as a insulin in/out addition of PRP during the use of fat graft.

Authors suggest that growth factors present in the PRP play a role in improving tissue healing. VEGF should be used to implement the neoangiogenesis in patients affected by vascular disease that has generated a loss of substance and which prevents or delays the healing process; the FGF may be used to implement the rejuvenation of the tissues and the PDGF-BB to implement chemotaxis and mitogenic effects. The perspective future start from the paper of Katz et al. [62] that describes the effect of human stromal cells derived from adipose tissue (ADSC) on pancreatic tumor cell proliferation.

\section{Consent}

A statement that the study was conducted with the understanding and the consent of the human subject.

\section{Conflict of Interests}

The authors confirm that there are no conflict of interests. The authors do not have a financial relation with the commercial identities mentioned in the paper.

\section{References}

[1] S. Sampson, M. Gerhardt, and B. Mandelbaum, "Platelet rich plasma injection grafts for musculoskeletal injuries: a review," Current Reviews in Musculoskeletal Medicine, vol. 1, pp. 165-174, 2008.

[2] C. J. Oon and J. R. Hobbs, "Clinical applications of the continuous flow blood separator machine," Clinical and Experimental Immunology, vol. 20, no. 1, pp. 1-16, 1975.

[3] M. Ferrari, S. Zia, and M. Valbonesi, "A new technique for hemodilution, preparation of autologous platelet-rich plasma and intraoperative blood salvage in cardiac surgery," International Journal of Artificial Organs, vol. 10, no. 1, pp. 47-50, 1987.

[4] D. H. Whitman, R. L. Berry, and D. M. Green, "Platelet gel: an autologous alternative to fibrin glue with applications in oral and maxillofacial surgery," Journal of Oral and Maxillofacial Surgery, vol. 55, no. 11, pp. 1294-1299, 1997.
[5] R. E. Marx, "Platelet-rich plasma: evidence to support its use," Journal of Oral and Maxillofacial Surgery, vol. 62, no. 4, pp. 489496, 2004.

[6] S. Bhanot and J. C. Alex, "Current applications of platelet gels in facial plastic surgery," Facial Plastic Surgery, vol. 18, no. 1, pp. 27-33, 2002.

[7] D. Man, H. Plosker, and J. E. Winland-Brown, "The use of autologous platelet-rich plasma (platelet gel) and autologous platelet-poor plasma (fibrin glue) in cosmetic surgery," Plastic and Reconstructive Surgery, vol. 107, no. 1, pp. 229-236, 2001.

[8] W. J. Welsh, "Autologous platelet gel: clinical function and usage in plastic surgery," Cosmetic Dermatology, vol. 11, article 13, 2000.

[9] Y. Liu, A. Kalén, O. Risto, and O. Wahlström, "Fibroblast proliferation due to exposure to a platelet concentrate in vitro is $\mathrm{pH}$ dependent," Wound Repair and Regeneration, vol. 10, no. 5, pp. 336-340, 2002.

[10] D. J. Margolis, J. Kantor, J. Santanna, B. L. Strom, and J. A. Berlin, "Effectiveness of platelet releasate for the treatment of diabetic neuropathic foot ulcers," Diabetes Care, vol. 24, no. 3, pp. 483488, 2001.

[11] E. Anitua, "Plasma rich in growth factors: preliminary results of use in the preparation of future sites for implants," International Journal of Oral and Maxillofacial Implants, vol. 14, no. 4, pp. 529$535,1999$.

[12] M. Sánchez, E. Anitua, J. Azofra, I. Andía, S. Padilla, and I. Mujika, "Comparison of surgically repaired Achilles tendon tears using platelet-rich fibrin matrices," American Journal of Sports Medicine, vol. 35, no. 2, pp. 245-251, 2007.

[13] M. Sánchez, E. Anitua, G. Orive, I. Mujika, and I. Andia, "Platelet-rich therapies in the treatment of orthopaedic sport injuries," Sports Medicine, vol. 39, no. 5, pp. 345-354, 2009.

[14] E. Anitua, G. Orive, J. J. Aguirre, B. Ardanza, and I. Andía, “5year clinical experience with BTI dental implants: risk factors for implant failure," Journal of Clinical Periodontology, vol. 35, no. 8, pp. 724-732, 2008.

[15] E. Anitua, J. J. Aguirre, J. Algorta et al., "Effectiveness of autologous preparation rich in growth factors for the treatment of chronic cutaneous ulcers," Journal of Biomedical Materials Research B, vol. 84, no. 2, pp. 415-421, 2008.

[16] E. Anitua, M. Sánchez, M. M. Zalduendo et al., "Fibroblastic response to treatment with different preparations rich in growth factors," Cell Proliferation, vol. 42, no. 2, pp. 162-170, 2009.

[17] V. Cervelli, P. Gentile, and M. Grimaldi, "Regenerative surgery: Use of fat grafting combined with platelet-rich plasma for chronic lower-extremity ulcers," Aesthetic Plastic Surgery, vol. 33, no. 3, pp. 340-345, 2009.

[18] S. R. Coleman, "Long-term survival of fat transplants: controlled demonstrations," Aesthetic Plastic Surgery, vol. 19, no. 5, pp. 421-425, 1995.

[19] S. R. Coleman, "Facial recountouring with lipostructure," Clinics in Plastic Surgery, vol. 24, no. 2, pp. 347-367, 1997.

[20] V. Cervelli, P. Gentile, M. G. Scioli et al., "Application of plateletrich plasma in plastic surgery: clinical and in vitro evaluation," Tissue Engineering C, vol. 15, no. 4, pp. 625-634, 2009.

[21] V. Cervelli, P. Gentile, B. De Angelis et al., "Application of enhanced stromal vascular fraction and fat grafting mixed with PRP in post-traumatic lower extremity ulcers," Stem Cell Research, vol. 6, no. 2, pp. 103-111, 2011.

[22] E. Anitua, "Plasma rich in growth factors: preliminary results of use in the preparation of future sites for implants," International 
Journal of Oral and Maxillofacial Implants, vol. 14, no. 4, pp. 529$535,1999$.

[23] E. Anitua, M. Sanchez, A. T. Nurden et al., "Autologous fibrin matrices: a potential source of biological mediators that modulate tendon cell activities," Journal of Biomedical Materials Research A, vol. 77, no. 2, pp. 285-293, 2006.

[24] W. J. Welsh, "Autologous platelet gel: clinical function and usage in plastic surgery," Cosmetic Dermatology, vol. 11, article 13, 2000.

[25] S. V. Kevy and M. S. Jacobson, "Comparison of methods for point of care preparation of autologous platelet gel," Journal of Extra-Corporeal Technology, vol. 36, no. 1, pp. 28-35, 2004.

[26] D. M. Arm, "Autologous platelet-based therapies for orthopaedic tissue regeneration," Orthopedics, vol. 25, p. 169, 2002.

[27] J. H. Waters and K. C. Roberts, "Database review of possible factors influencing point-of-care platelet gel manufacture," Journal of Extra-Corporeal Technology, vol. 36, no. 3, pp. 250-254, 2004.

[28] P. Rožman and Z. Bolta, "Use of platelet growth factors in treating wounds and soft-tissue injuries," Acta Dermatovenerologica Alpina, Pannonica et Adriatica, vol. 16, no. 4, pp. 156-165, 2007.

[29] D. Man, H. Plosker, and J. E. Winland-Brown, "The use of autologous platelet-rich plasma (platelet gel) and autologous platelet-poor plasma (fibrin glue) in cosmetic surgery," Plastic and Reconstructive Surgery, vol. 107, no. 1, pp. 229-236, 2001.

[30] S. Marlovits, M. Mousavi, C. Gäbler, J. Erdös, and V. Vécsei, “A new simplified technique for producing platelet-rich plasma: a short technical note," European Spine Journal, vol. 13, pp. S102S106, 2004.

[31] J. L. Lozada, N. Caplanis, P. Proussaefs, J. Willardsen, and G. Kammeyer, "Platelet-rich plasma application in sinus graft surgery: part I-background and processing techniques," The Journal of Oral Implantology, vol. 27, no. 1, pp. 38-42, 2001.

[32] A. G. Hood and D. M. Arm, "Topical application of autogenous tissue growth factors for augmentation of structural bone graft fusion," in Proceedings of the American Society of ExtraCorporeal Technology 11th Annual Symposium on New Advances in Blood Management, Las Vegas, Nev, USA, April 2004.

[33] D. M. Arm, "Characterization of an autologous platelet gel containing multiple growth factors," in Proceedings of the 45th Annual Meeting of the Orthopaedic Research Society, Anaheim, Calif, USA, February 1999.

[34] J.-L. Foyatier, A. Mojallal, D. Voulliaume, and J.-P. Comparin, "Clinical evaluation of structural fat tissue graft (Lipostructure) in volumetric facial restoration with face-lift. About 100 cases," Annales de Chirurgie Plastique et Esthetique, vol. 49, no. 5, pp. 437-455, 2004.

[35] V. Cervelli and P. Gentile, "Use of cell fat mixed with platelet gel in progressive hemifacial atrophy," Aesthetic Plastic Surgery, vol. 33, no. 1, pp. 22-27, 2009.

[36] M. Grimaldi, P. Gentile, L. Labardi, E. Silvi, A. Trimarco, and V. Cervelli, "Lipostructure technique in Romberg syndrome," Journal of Craniofacial Surgery, vol. 19, no. 4, pp. 1089-1091, 2008.

[37] J. B. Mitchell, K. McIntosh, S. Zvonic et al., "Immunophenotype of human adipose-derived cells: temporal changes in stromalassociated and stem cell-associated markers," Stem Cells, vol. 24, no. 2, pp. 376-385, 2006.

[38] K. McIntosh, S. Zvonic, S. Garrett et al., "The immunogenicity of human adipose-derived cells: temporal changes in vitro," Stem Cells, vol. 24, no. 5, pp. 1246-1253, 2006.
[39] X. Bai, S. Sadat, S. Gehmert, E. Alt, and Y. Song, "VEGF receptor Flk-1 plays an important role in c-kit expression in adipose tissue derived stem cells," FEBS Letters, vol. 581, no. 24, pp. 46814684, 2007.

[40] P. S. Petrungaro, "Using platelet-rich plasma to accelerate soft tissue maturation in esthetic periodontal surgery," Compendium of Continuing Education in Dentistry, vol. 22, no. 9, pp. 729-746, 2001.

[41] M. Robiony, F. Polini, F. Costa, and M. Politi, "Osteogenesis distraction and platelet-rich plasma for bone restoration of the severely atrophic mandible: preliminary results," Journal of Oral and Maxillofacial Surgery, vol. 60, no. 6, pp. 630-635, 2002.

[42] A. della Valle, G. Sammartino, G. Marenzi et al., "Prevention of postoperative bleeding in anticoagulated patients undergoing oral surgery: use of platelet-rich plasma gel," Journal of Oral and Maxillofacial Surgery, vol. 61, no. 11, pp. 1275-1278, 2003.

[43] R. E. Marx, E. R. Carlson, R. M. Eichstaedt, S. R. Schimmele, J. E. Strauss, and K. R. Georgeff, "Platelet-rich plasma: growth factor enhancement for bone grafts," Oral Surgery, Oral Medicine, Oral Pathology, Oral Radiology, and Endodontics, vol. 85, no. 6, pp. 638-646, 1998.

[44] B. Bose and M. A. Balzarini, "Bone graft gel: autologous growth factors used with autograft bone for lumbar spine fusions," Advances in Therapy, vol. 19, no. 4, pp. 170-175, 2002.

[45] H. T. Hee, M. E. Majd, R. T. Holt, and L. Myers, "Do autologous growth factors enhance transforaminal lumbar interbody fusion?" European Spine Journal, vol. 12, no. 4, pp. 400-407, 2003.

[46] G. L. Lowery, S. Kulkarni, and A. E. Pennisi, "Use of autologous growth factors in lumbar spinal fusion," Bone, vol. 25, supplement 2, p. 47S, 1999.

[47] A. J. DelRossi, A. C. Cernaianu, R. A. Vertrees et al., "Plateletrich plasma reduces postoperative blood loss after cardiopulmonary bypass," Journal of Thoracic and Cardiovascular Surgery, vol. 100, no. 2, pp. 281-286, 1990.

[48] B. Nedelec, H. A. Shankowsky, and E. E. Tredget, "Rating the resolving hypertrophic scar: comparison of the Vancouver Scar Scale and scar volume," Journal of Burn Care and Rehabilitation, vol. 21, no. 3, pp. 205-212, 2000.

[49] K. Kazakos, D. N. Lyras, D. Verettas, K. Tilkeridis, and M. Tryfonidis, "The use of autologous PRP gel as an aid in the management of acute trauma wounds," Injury, vol. 40, no. 8, pp. 801-805, 2008.

[50] G. Crovetti, G. Martinelli, M. Issi et al., "Platelet gel for healing cutaneous chronic wounds," Transfusion and Apheresis Science, vol. 30, no. 2, pp. 145-151, 2004.

[51] J. P. McAlee, E. Kaplan, and G. Persich, "Efficacy of concentrated autologous platelet-derived growth factors in chronic lowerextremity wounds," Journal of the American Podiatric Medical Association, vol. 96, no. 6, pp. 482-488, 2006.

[52] G. Rigotti, A. Marchi, P. Stringhini et al., "Determining the oncological risk of autologous lipoaspirate grafting for postmastectomy breast reconstruction," Aesthetic Plastic Surgery, vol. 34, no. 4, pp. 475-480, 2010.

[53] D. M. Powell, E. Chang, and E. H. Farrior, "Recovery from deepplane rhytidectomy following unilateral wound treatment with autologous platelet gel: a pilot study," Archives of Facial Plastic Surgery, vol. 3, no. 4, pp. 245-250, 2001.

[54] D. Man, H. Plosker, and J. E. Winland-Brown, "The use of autologous platelet-rich plasma (platelet gel) and autologous platelet-poor plasma (fibrin glue) in cosmetic surgery," Plastic and Reconstructive Surgery, vol. 107, no. 1, pp. 229-237, 2001. 
[55] J. M. Anderson, "The cellular cascades of wound healing," in Bone Engineering, J. E. Davies, Ed., pp. 81-93, em Squared, Toronto, Canada, 2000.

[56] J. Guerrerosantos, F. Guerrerosantos, and J. Orozco, "Classification and treatment of facial tissue atrophy in Parry-Romberg disease," Aesthetic Plastic Surgery, vol. 31, no. 5, pp. 424-434, 2007.

[57] K. Yoshimura, K. Sato, N. Aoi, M. Kurita, T. Hirohi, and K. Harii, "Cell-assisted lipotransfer for cosmetic breast augmentation: supportive use of adipose-derived stem/stromal cells," Aesthetic Plastic Surgery, vol. 32, no. 1, pp. 48-55, 2008.

[58] B. Azzena, F. Mazzoleni, G. Abatangelo, B. Zavan, and V. Vindigni, "Autologous platelet-rich plasma as an adipocyte in vivo delivery system: case report," Aesthetic Plastic Surgery, vol. 32, no. 1, pp. 155-158, 2008.

[59] M. L. Zocchi, "Discussion: autologous platelet-rich plasma as an adipocyte in vivo delivery system," Aesthetic Plastic Surgery, vol. 32, no. 1, pp. 159-161, 2008.

[60] A. Sen, Y. R. Lea-Currie, D. Sujkowska et al., "Adipogenic potential of human adipose derived stromal cells from multiple donors is heterogeneous," Journal of Cellular Biochemistry, vol. 81, pp. 312-319, 2001.

[61] S. Bhanot and J. C. Alex, "Current applicationsof platelet gels in facial plastic surgery," Facial Plastic Surgery, vol. 18, no. 1, pp. 27-33, 2002.

[62] A. J. Katz, A. Tholpady, S. S. Tholpady, H. Shang, and R. C. Ogle, "Cell surface and transcriptional characterization of human adipose-derived adherent stromal (hADAS) cells," Stem Cells, vol. 23, no. 3, pp. 412-423, 2005. 


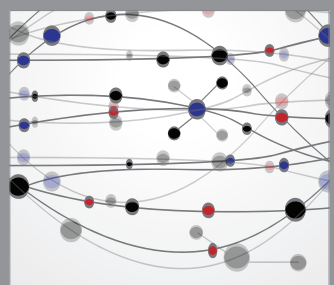

The Scientific World Journal
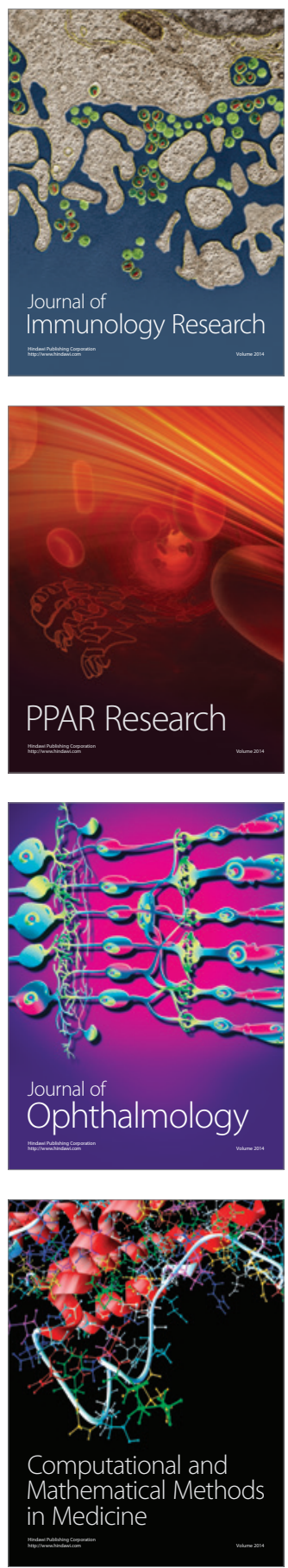

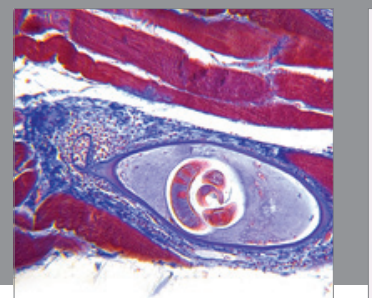

Gastroenterology

Research and Practice
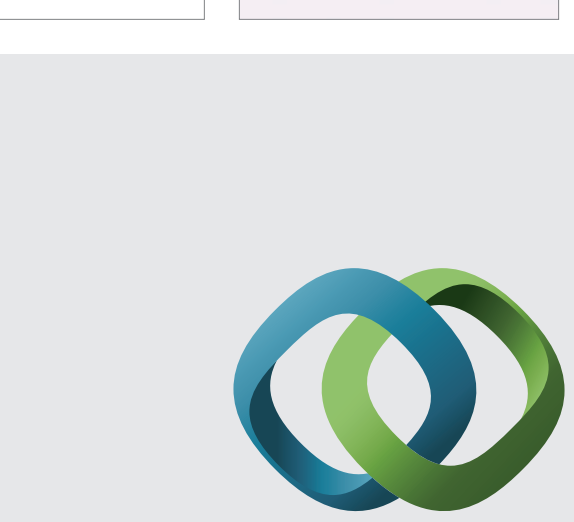

\section{Hindawi}

Submit your manuscripts at

http://www.hindawi.com
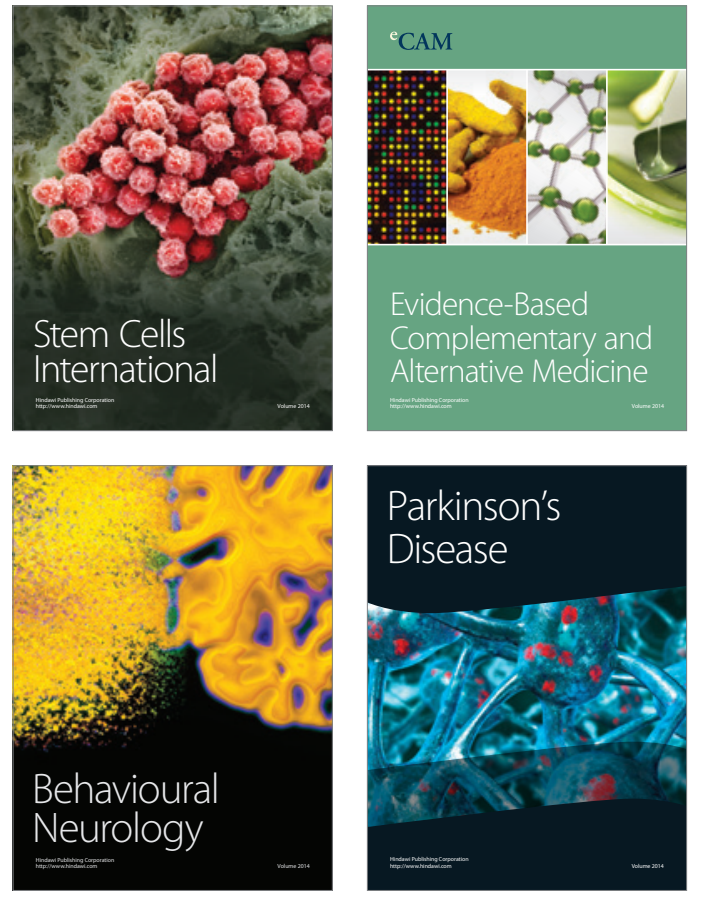
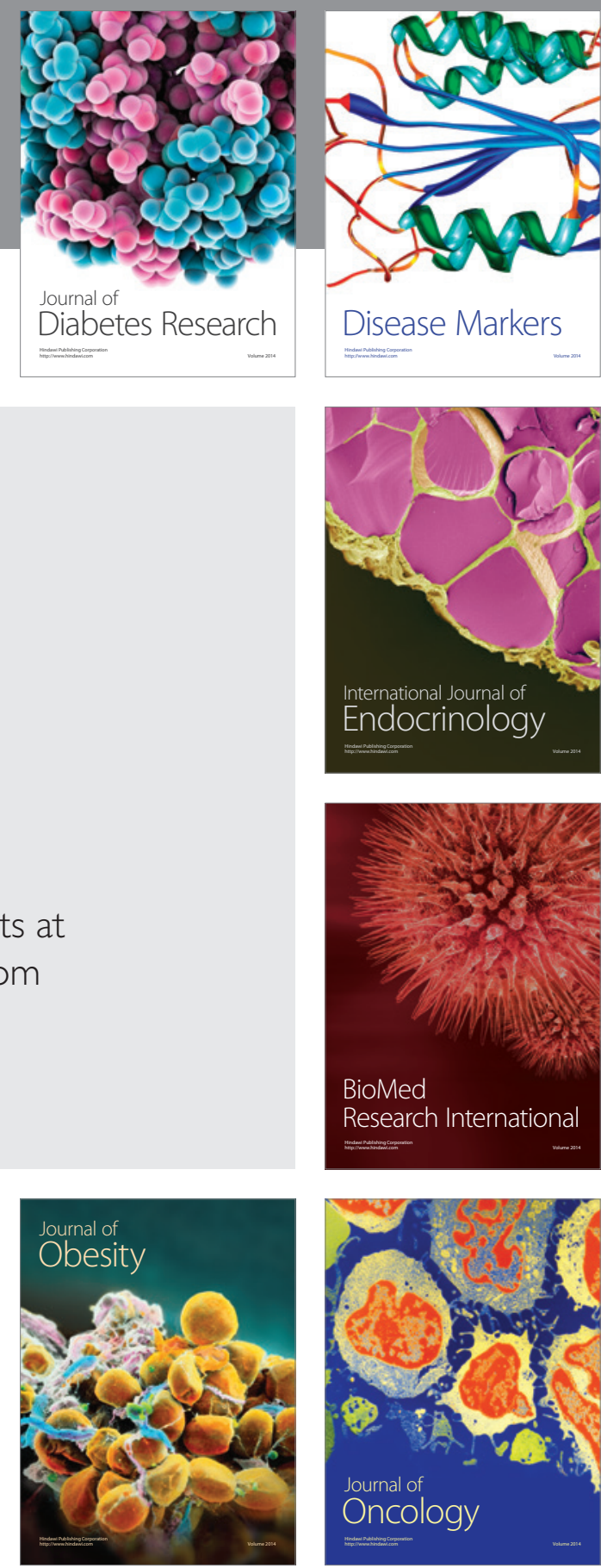

Disease Markers
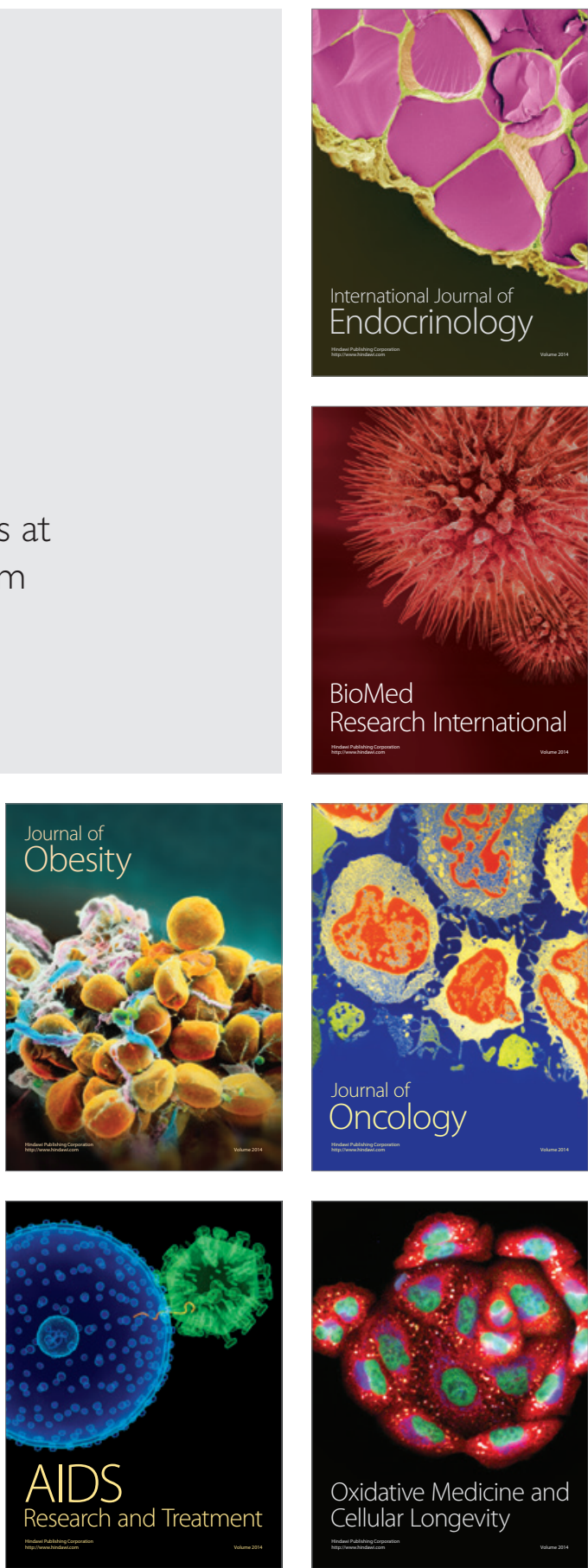